\title{
The ocean's role in setting the mean position of the Inter-Tropical Convergence Zone
}

\author{
J. Marshall • A. Donohoe $\cdot$ D. Ferreira $\cdot$ \\ D. McGee
}

Received: 7 December 2012/ Accepted: 8 April 2013/Published online: 1 May 2013

(c) The Author(s) 2013. This article is published with open access at Springerlink.com

\begin{abstract}
Through study of observations and coupled climate simulations, it is argued that the mean position of the Inter-Tropical Convergence Zone (ITCZ) north of the equator is a consequence of a northwards heat transport across the equator by ocean circulation. Observations suggest that the hemispheric net radiative forcing of climate at the top of the atmosphere is almost perfectly symmetric about the equator, and so the total (atmosphere plus ocean) heat transport across the equator is small (order 0.2 PW northwards). Due to the Atlantic ocean's meridional overturning circulation, however, the ocean carries significantly more heat northwards across the equator (order $0.4 \mathrm{PW}$ ) than does the coupled system. There are two primary consequences. First, atmospheric heat transport is southwards across the equator to compensate (0.2 PW southwards), resulting in the ITCZ being displaced north of the equator. Second, the atmosphere, and indeed the ocean, is slightly warmer (by perhaps $2{ }^{\circ} \mathrm{C}$ ) in the northern hemisphere than in the southern hemisphere. This leads to the northern hemisphere emitting slightly more outgoing longwave radiation than the southern hemisphere by virtue of its relative warmth, supporting the small northward heat transport by the coupled system across the equator. To conclude, the coupled nature of the problem is illustrated through study of atmosphere-oceanice simulations in the idealized setting of an aquaplanet, resolving the key processes at work.
\end{abstract}

Keywords Ocean - Heat transport - ITCZ - Energy balance

J. Marshall $(\bowtie) \cdot$ A. Donohoe · D. Ferreira · D. McGee EAPS, Massachusetts Institute of Technology (MIT),

77 Massachusetts. Av., Cambridge, MA, USA

e-mail: jmarsh@mit.edu

\section{Introduction}

A primary asymmetric feature of the global climate is the displacement of the Inter-Tropical Convergence Zone (ITCZ) northward of the equator. If the climate did not exhibit any inter-hemispheric asymmetries the ITCZ would 'follow the sun' over the seasonal cycle and, in the annualmean, be centered over the equator. However, as is very clear from Fig. 1, which shows the annual-mean precipitation, both in plan view and zonal-average, the ITCZ (here defined in terms of the latitude of maximum precipitation at each longitude) is located around $5^{\circ} \mathrm{N}$, distinctly north of the equator.

Classically the ITCZ position can be interpreted as an atmospheric response to regional sea-surface-temperature (SST) anomalies, as in Philander et al. (1996) and references therein. Regional details of the tropical SST distribution and continental configurations play an important role. Extra-tropical forcing can also influence the position and shifts of the ITCZ (see Frierson and Hwang 2012). Here, instead, we stand back from detailed dynamical considerations to invoke constraints on global and hemispheric energy balance, to argue that the northward displacement of the ITCZ from the equator can be traced back to cross-equatorial ocean heat transport (OHT) associated with ocean circulation in the Atlantic sector. The Atlantic ocean's meridional overturning circulation (MOC) results in order $0.4 \mathrm{PW}$ of heat transport northward across the equator. The top-of-the-atmosphere (TOA) net radiation is nearly symmetric about the equator and so the total (atmosphere plus ocean) energy transport at the equator is small, smaller than the northward transport achieved by ocean circulation. Thus northward ocean heat transport is largely compensated by southward atmospheric heat transport. This is achieved, we argue, by shifting the 


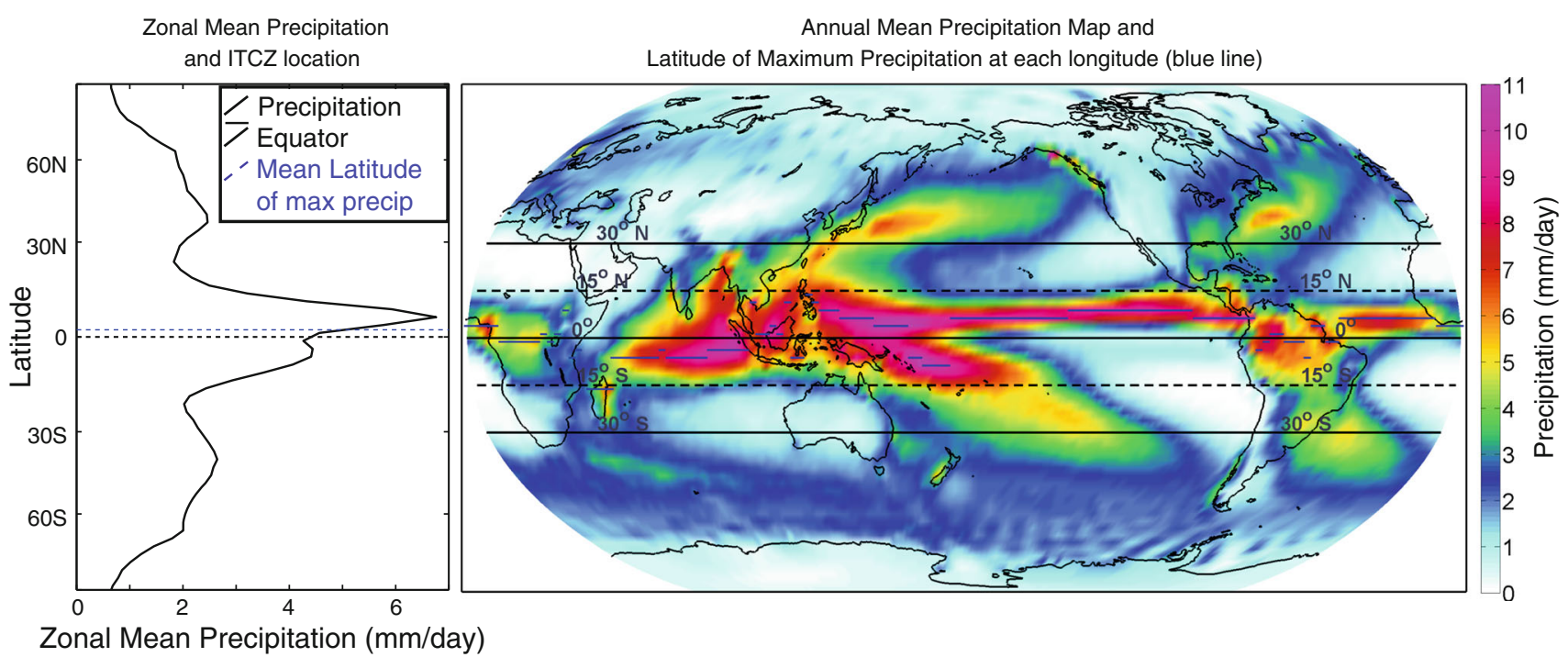

Fig. 1 The annual mean precipitation from the National Oceanographic and Atmospheric Administration's Climate Prediction Center's (NOAACPC) merged analysis (Xie and Arkin 1996). Blue lines indicate the meridional location of the maximum in the Tropics at

tropical circulation pattern and its ITCZ northward of the equator.

The association of ITCZ position with demands of global energy balance has slowly been emerging in the literature. The connection is implicit in the work of Zhang and Delworth (2005) who noted the shift of the ITCZ on to the equator following the collapse of the ocean's MOC in a coupled climate model. Broccoli et al. (2006) carry out perturbation (slab) experiments with cooling of the Northern Hemisphere/warming of Southern Hemisphere (implicitly imposing a southward OHT), and observe enhanced northward atmospheric heat transport across the equator (in compensation), and a southward displacement of the ITCZ. Recently, Fuckar et al. (2013), using an idealized sector coupled general circulation model (GCM), observe that symmetry breaking of the ocean's MOC, with deep convection in one hemisphere and upwelling in the other, leads to a cross equatorial OHT (toward the convective hemisphere), a partial compensating atmospheric energy transport and a small displacement of the ITCZ from the equator. Frierson et al. (2013) make the connection between the hemispheric energy flow and ITCZ more explicit; they argue that the ITCZ's location north of the equator requires that the atmosphere be heated more strongly in the northern hemisphere $(\mathrm{NH})$ than in the southern hemisphere ( $\mathrm{SH})$. They find that, as argued here, the hemispheric asymmetry of atmospheric heating in the observed climate system is primarily due to OHT across the equator as opposed to radiation at the TOA. They also find that they could reproduce the ITCZ's location north of the equator in a slab ocean aquaplanet with a prescribed each longitude. The zonal mean is shown on the left and is co-plotted with the zonal mean of the local maximum (blue lines) and the precipitation centroid (dashed black lines)

OHT across the equator which argued for the role of the OHT in setting the ITCZ location.

In this paper, we extend the observational calculations of the hemispheric asymmetry of energy input into the atmosphere to include additional data sets, explore the uncertainties in these calculations and the processes controlling the hemispheric differences in energy budgets and cross-equatorial heat exchange. We also demonstrate the role of OHT in setting the ITCZ location in an idealized, coupled system that resolves the key dynamical processes at work, rather than an atmosphere coupled to a slab ocean with prescribed OHT. Our account is set out as follows. In Sect. 2 we discuss the position of the ITCZ from the perspective of global energy balance through diagnosis of contemporary reanalysis fields and satellite radiation data. In Sect. 3 we present idealized coupled climate model experiments of aqua-planets which clearly illustrate the principles involved and allow us to directly link interhemispheric asymmetries in climate to cross-equatorial heat transport in the ocean due to its MOC. In Sect. 4 we present a discussion and conclude.

\section{ITCZ position and cross-equatorial heat transport: inferences from observations}

In this section we use observations to demonstrate that:

1. The ITCZ is located north of the equator and collocated with the ascending branch of the Hadley cell (Sect. 2.1), 
2. The resulting cross-equatorial heat transport by the atmosphere is southward, of order $-0.2 \pm 0.1 \mathrm{PW}$ (Sect. 2.2),

3. Hemispheric asymmetries in TOA energy budgets demand a northward total (atmosphere plus ocean), energy flux across the equator of order $0.2 \pm 0.1 \mathrm{PW}$, which must therefore be achieved by ocean circulation (Sect. 2.3). A significant northward OHT is implied of order $0.4 \pm 0.1 \mathrm{PW}$, consistent with inferences from contemporary in-situ ocean observations.

Before going on we immediately present the "big picture' in Fig. 2 where estimates of the size of the terms in the energy budget are given in schematized form. The hemispheric energy budget requires that the total (atmosphere plus ocean) heat transport across the equator is balanced by asymmetric net energy input at the TOA.

The observations suggest that there is a net radiative loss at the TOA in the NH and gain in the SH. Therefore, in the absence of other processes, the atmospheric heat transport would have to be directed northward across the equator. Given that the atmospheric energy transport in the deep tropics is dominated by the meridional overturning circulation, the ITCZ would have to be located south of the equator to achieve the necessary transport. This is contrary to observations. Instead the required northward energy flux

\section{Atmospheric/ocean heat transport across the equator}
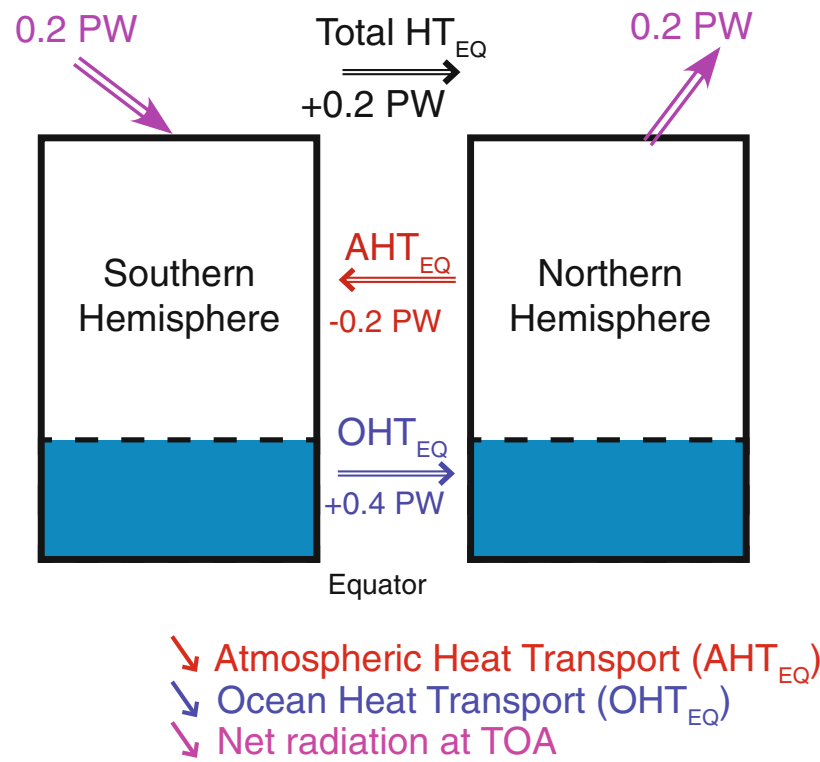

Fig. 2 Energy input at the TOA and its relationship to energy flux across the equator. $\mathrm{AHT}_{E Q}$ and $\mathrm{OHT}_{E Q}$ are the atmospheric and oceanic heat transport across the equator respectively. The numbers are estimates obtained in this study using observational reanalysis and satellite data. The error bars in all fluxes are order $\pm 0.1 \mathrm{PW}$. OHT transport is estimated as a residual is achieved by the ocean. Observations suggest that this ocean heat transport is comparable to, and somewhat larger than the radiative loss at the TOA in the $\mathrm{NH}$. We surmise that the location of the ITCZ north of the equator could not be achieved in the absence of ocean energy transport across the equator and its position must therefore be considered a result of that ocean transport.

The error bars in the estimates of Fig. 2 are significant ( $\pm 0.1 \mathrm{PW}$ is likely a lower bound) and so we must proceed with care. Indeed observations alone cannot give us unequivocal answers to the questions we seek and so we follow up in Sect. 3 with a coupled modeling study that explores the same issues but in a controlled setting.

\subsection{Tropical precipitation as a proxy for ITCZ position} and its relationship to the Hadley cell

The annual mean tropical precipitation is asymmetric about the Equator (see Fig. 1) with more rainfall falling north of the equator, especially in the Pacific sector. As a consequence, the zonal mean precipitation has a maximum around $5^{\circ} \mathrm{N}$ of the equator. Indeed all metrics of ITCZ location used in the literature-e.g., the latitude of maximum zonal mean precipitation used by Xian and Miller (2008), the zonal average of the latitude of maximum precipitation at each longitude as in Waliser and Gautier (1993) or the precipitation centroid used by Frierson and Hwang (2012) - place the annual mean ITCZ north of the Equator.

The annual mean meridional atmospheric overturning streamfunction is calculated from the zonal and time mean velocities in the ECMWF reanalysis (ERA) for the period 1979-2006, and is co-plotted with the precipitation in Fig. 3. The tropical precipitation maximum is collocated with the ascending branch of the Hadley cell and is north of the Equator. As a consequence, there is northward mass transport at the surface and southward mass transport aloft. Given that moist static energy (MSE) ${ }^{1}$ generally increases with height, one might therefore expect, and indeed one observes (see next Section), a net southward atmospheric energy transport across the equator associated with the Hadley Circulation.

\subsection{The atmospheric heat transport across the equator}

It is often assumed that atmospheric eddies transport less energy in the deep tropics than the overturning circulation (Held 2001) and, thus, the total energy transport across the

\footnotetext{
${ }^{1}$ Moist static energy is the sum of sensible, latent, and potential energy $M S E=c_{p} T+L q+g z$ where $c_{p}$ is the specific heat at constant pressure, $T$ is the temperature, $L$ is the latent heat, $q$ is the specific humidity, $g$ is gravity and $z$ is height.
} 

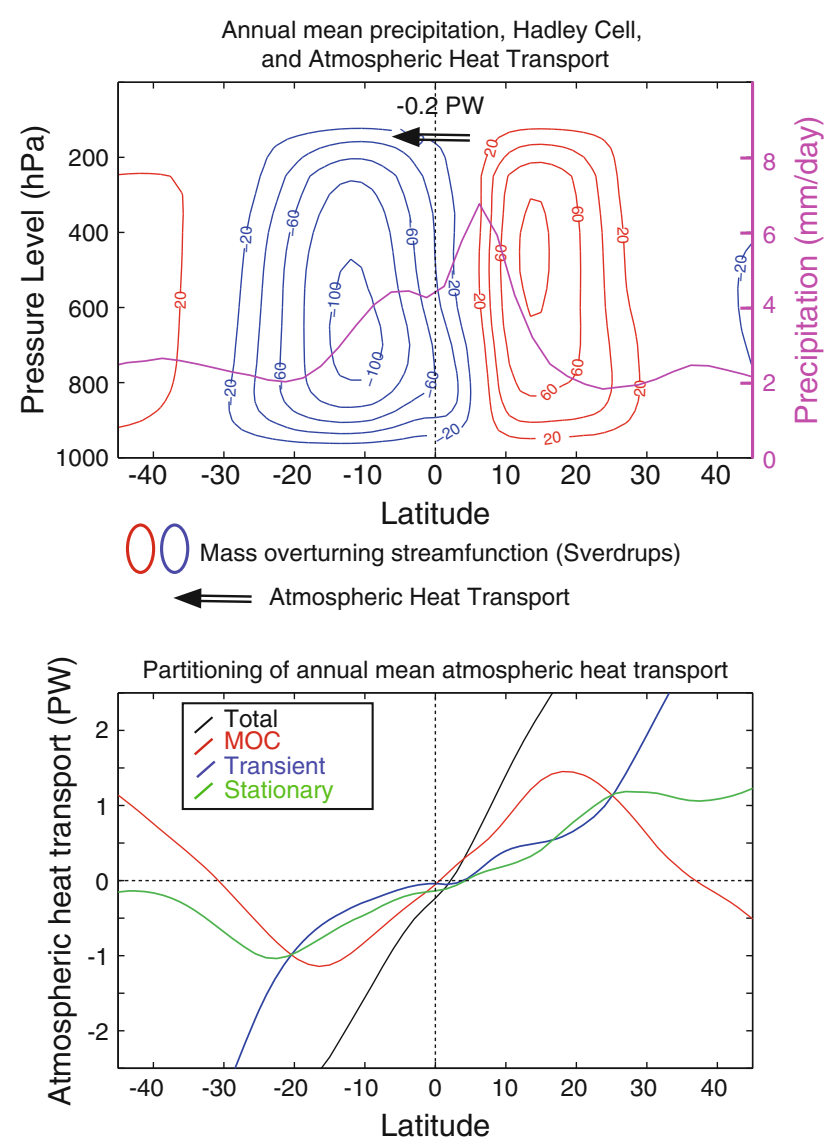

Fig. 3 The red (clockwise) and blue (anticlockwise) streamfunction of annual-mean overturning circulation derived from the ERA reanalysis. The contour interval is 20 Sverdrup (Sv) where $1 \mathrm{~Sv}=$ $10^{9} \mathrm{~kg} \mathrm{~s}^{-1}$ as in Czaja and Marshall (2006). The purple line is the annual and zonal mean precipitation in $\mathrm{mm} \mathrm{day}^{-1}$ with values given by the purple axis to the right. The black arrow indicates the atmospheric heat transport derived from the ERA re-analysis in this study (see Table 2). (Bottom) The partitioning of annual-mean atmospheric heat transport between MOC, transient and stationary eddies

equator is achieved by the MOC. We now test this assumption by calculating the eddy and MOC contributions to energy transport across the equator from re-analysis data.

We calculate the atmospheric energy transport at the equator using two different sets of re-analysis data. The NCEP reanalysis fields (Kalnay and Coauthors 1996) with a (horizontal) spectral resolution of T62 and 17 vertical levels are analyzed over the 1979-2006 time period. A separate analysis is carried out with the ERA interim analysis which has a horizontal resolution of $1.5^{\circ}$ and 37 vertical levels. Calculations are performed over the same period with both analysis products using 6 hourly fields. The velocities and MSE are subdivided into the zonal and time mean, transient eddy, and stationary eddy components (Priestley 1948; Lorenz 1953). In this framework, the vertically integrated (from $p=p_{s}$ to $p=0$ ) atmospheric energy transport is:

$$
\begin{aligned}
A H T(\phi)= & -\frac{2 \pi a \cos (\phi)}{g} \int_{p_{s}}^{0} \underbrace{[\bar{V}][\overline{M S E}]}_{M O C}+\underbrace{\overline{[V]^{\prime}[M S E]^{\prime}}}_{\text {TOC }} \\
& +\underbrace{\left[V^{*} M S E^{*}\right]}_{\text {Stat.eddy }}+\underbrace{\left[\overline{\left.V^{* \prime} M S E^{* \prime}\right]}\right.}_{\text {Trans.eddy }} d p
\end{aligned}
$$

where $V$ is the meridional velocity, $a$ is the radius of the earth, $\phi$ the latitude and $g$ the acceleration due to gravity. Here - denote time averages, [.] are zonal averages, primes (') are departures from the time average and asterisks (*) are departures from the zonal average. The first term is the energy transport associated with the time and zonal average MOC. The second term is the energy transport associated with the covariance of the zonal mean overturning circulation and the vertical stratification which we call the transient overturning circulation (TOC); it is two orders of magnitude smaller than the MOC and makes a negligible contribution to all quantities discussed here. The third and fourth terms are contributions from stationary and transient eddy transports.

The MOC energy transport in Eq. (1) can be rewritten by decomposing the MSE and V into a vertical average (denoted by curly brackets, \{\} ) and a departure from the vertical average (denoted by tildes):

$$
\int_{p_{s}}^{0}[\bar{V}][\overline{M S E}] d p=\int_{p_{s}}^{0}(\{V\}\{M S E\}+\widetilde{V} \widetilde{M S E}) d p
$$

Here $\{V\}$ is zero provided that there is no mass flow across a latitude circle. However $\{V\}$ is non-zero on seasonal timescales owing to surface pressure tendencies on monthly timescales. Taking in to account these mass tendencies following (Trenberth and Stepaniak 2003) we find that the monthly values of the first term of Eq. (2) are two orders of magnitude smaller than the second term and have an annual mean value that is three orders of magnitude smaller than the second term. ${ }^{2}$ We thus conclude that the annual mean energy transport by the MOC across the equator is well approximated by the second term on the rhs of Eq. (2). As is intuitively satisfying, energy is transported in the direction of the flow in the upper atmosphere, since $\widetilde{M S E}$ is positive.

On evaluating all terms in Eq. (1), we find an annual mean $A H T_{E Q}$ of $-0.13 \pm 0.07 \mathrm{PW}$ (i.e. southwards) from the NCEP reanalyses and $-0.23 \pm 0.04 \mathrm{PW}$ from the ERA

\footnotetext{
2 This term is non-zero in the annual mean because: (1) there is a seasonal covariance of $\{V\}$ and $\{M S E\}$ and (2) the annual mean $\{V\}$ is not identically zero but is balanced by the mass flux associated evaporation minus precipitation.
} 
reanalyses. The quoted error bounds are for the $95 \%$ confidence interval based on the inter-annual variability. These errors do not include uncertainties due to systematic errors in the reanalysis and should be considered lower bounds.

The decomposition of $A H T_{E Q}$ into MOC, stationary and transient eddies is shown in Table 1 and reveal discrepancies between the two reanalyses and some counterintuitive features. Most notably the MOC heat transport is northward $(+0.15 \mathrm{PW})$ in the NCEP reanalysis despite the predominance of a counterclockwise rotating cell at the Equator (Fig. 3). This is because there is a small northward flow in the stratosphere (above $100 \mathrm{hPa}$ and extending to $20 \mathrm{hPa}$ ) where $\widetilde{M S E}$ has large positive values corresponding to an equivalent potential temperature contrast of order $200 \mathrm{~K}$. In comparison, the vertical contrast of equivalent potential temperature associated with the mass fluxes in the upper and lower branch of the Hadley cell is of order $15 \mathrm{~K}$ for seasonal variations in the MOC intensity (Donohoe et al. 2012). Thus, the total heat transport associated with the MOC is rather sensitive to small meridional velocities in the upper stratosphere. This same feature is less pronounced in the ERA reanalysis which has an annual MOC energy transport of $-0.05 \mathrm{PW}$. The annual mean stationary and transient eddy energy transport at the equator are southward in both the NCEP and ERA reanalysis and have non-negligible magnitudes, a point made by Heaviside and Czaja (2012). We also note that there is a zonal mean southward flow at $700 \mathrm{hPa}$ over the equator in both sets of reanalysis. This flow occurs at the vertical minimum of MSE and leads to positive $A H T_{E Q}$ in the atmosphere's MOC. The stationary eddy energy transport is associated with low level (below $800 \mathrm{hPa}$ ) moisture transport in the Pacific sector (not shown). These results collectively suggest that $A H T_{E Q}$ is southward but that the relationship to the MOC in the atmosphere is not as straightforward as one might have expected, and standing eddies can play a non-negligible role. However the meridional gradient in AHT in the vicinity of the equator is dominated by the MOC component (see Fig. 3, bottom) which varies by order $0.1 \mathrm{PW}$ per degree of latitude. Therefore any northward shift of the atmosphere's overturning pattern would be anticipated to lead to a southward $A H T_{E Q}$ and vice versa.

We also calculate the annual mean $A H T_{E Q}$ from the atmospheric energy flux calculation of Fasullo and Trenberth (2008b) which are derived from the NCEP reanalysis at T67 resolution and from the results of Trenberth and Smith (2008) based on the Japanese Reanalysis (JRA). The NCEP derived calculations give an annual mean $A H T_{E Q}$ that is not significantly different from zero and the JRA calculations find a value of $-0.4 \pm 0.1 \mathrm{PW}$. The separation of $A H T_{E Q}$ into MOC and eddy components is not possible from the output fields provided in these studies. However, the separation into moist and dry components is possible and shows large discrepancies between these two sets of analysis (Table 1). The total $A H T_{E Q}$ is the small residual of a northward moisture transport and a southward dry energy transport that is slightly larger in magnitude. This result is expected for a counter-clockwise MOC circulation at the equator in a column that is moist at the surface and stably stratified.

In summary, the results of the calculation presented here with the ERA and NCEP reanalysis and the calculations of Fasullo and Trenberth (2008b) and Trenberth and Smith (2008) collectively suggest that the annual mean $A H T_{E Q}$ is southward and is of order $-0.2 \pm 0.1 \mathrm{PW}$ as set out in Table 1. This result is in accord with our expectations. However, in the observations there does not appear to be a direct connection between the mean position of the atmospheric MOC, and hence the ascending branch of the Hadley cell, and cross-equatorial heat transport. The observations are ambiguous with inconsistencies between analysis products. In Sect. 3, therefore, we will turn to a

Table 1 The atmospheric heat transport across the equator in PW and its partitioning into contributions from the mass overturning circulation, stationary eddies, and transient eddies

\begin{tabular}{|c|c|c|c|c|}
\hline & Total & Overturning & Stationary & Transient \\
\hline \multicolumn{5}{|c|}{ Observed atmospheric heat transport at the equator-this study (PW) } \\
\hline NCEP T62 & $-0.13 \pm 0.07$ & $+0.15 \pm 0.06$ & $-0.23 \pm 0.03$ & $-0.05 \pm 0.01$ \\
\hline \multirow[t]{2}{*}{ ERA } & $-0.23 \pm 0.04$ & $-0.05 \pm 0.04$ & $-0.14 \pm 0.03$ & $-0.04 \pm 0.01$ \\
\hline & Total & Moist & Dry & \\
\hline \multicolumn{5}{|c|}{ Estimates from Fasullo and Trenberth (2008b) } \\
\hline NCEP T67 & $0.0 \pm 0.1$ & $+2.0 \pm 0.2$ & $-2.0 \pm 0.3$ & \\
\hline JRA & $-0.4 \pm 0.1$ & $+4.4 \pm 0.4$ & $-4.8 \pm 0.5$ & \\
\hline
\end{tabular}

Calculations from both the NCEP reanalysis and ERA interim re-analysis are shown. The uncertainties are inferred from the $95 \%$ confidence interval of the inter-annual variability 
numerical model to explore further. Before proceeding to models, however, we now consider observations of the TOA radiation budget.

\subsection{The hemispheric asymmetry of radiation at the top of the atmosphere}

We have demonstrated that the annual mean $A H T_{E Q}$ is likely directed from the $\mathrm{NH}$ to the $\mathrm{SH}$ and so must be balanced by either a net radiative input at the TOA in the $\mathrm{NH}$ relative to the $\mathrm{SH}$ or by ocean heat transport into the $\mathrm{NH}$. This motivates the following analysis of the hemispheric asymmetry in radiative forcing of the planet. We find that the observations indicate that rather than a surplus of radiative forcing the $\mathrm{NH}$ experiences a deficit relative to the $\mathrm{SH}$, strongly suggesting that we must invoke northward heat transport across the equator by the ocean.

We analyze TOA radiation from two sets of satellite data: Earth's Radiation Budget Experiment (ERBE) and Clouds and Earth's Radiant Energy System (CERES) experiment. We use the ERBE climatological average fields over the 1985-1989 period (Barkstrom et al. 1989; Barkstrom and Hall 1982). The CERES data cover the 2000-2005 time period (Wielicki et al. 1996). We use long term climatologies of the TOA fluxes that are corrected for missing data as in Fasullo and Trenberth (2008a).

Global mean energy balance requires that the global average net radiative flux at the TOA is identically zero; the net radiative surplus over one hemisphere must be exactly balanced by a net radiative deficit over the other hemisphere supporting an energy flux by the combined atmosphere-ocean system across the equator. Global mean energy balance is not satisfied in either ERBE (Trenberth et al. 2009) or CERES (Kato et al. 2006) data due to instrumental and observational errors. For this reason we define $<N E T_{T O A}>$, as half the difference between the integrated net radiation in the $\mathrm{NH}$ minus that in the $\mathrm{SH}$; this definition implicitly ensures global energy balance and calculates the hemispheric asymmetry in radiative input over the two hemispheres.

The hemispheric asymmetry of net radiation, defined as positive when there is a deficit of radiation in the $\mathrm{NH}$, can be further decomposed into shortwave and longwave components thus:

$$
\begin{aligned}
<N E T_{T O A}> & =A H T_{E Q}+O H T_{E Q} \\
& =<S W_{N E T}>+<O L R>
\end{aligned}
$$

where the $<>$ brackets indicate half the difference between the integral in the $\mathrm{NH}$ and that in the $\mathrm{SH}$ and all fluxes are counted as positive when directed upward. Note $<S W_{N E T}>$ is positive if the $\mathrm{NH}$ absorbs less shortwave radiation than the $\mathrm{SH}$ and $\angle O L R>$ is positive if the $\mathrm{NH}$ emits more longwave radiation than the $\mathrm{SH}$.
In the ERBE data, the $\mathrm{NH}$ receives a deficit of net radiation: $\angle N E T_{T O A}>$ is $0.20 \mathrm{PW}$ and is decomposed into a $0.17 \mathrm{PW}$ contribution from $\angle O L R>$ and a $0.03 \mathrm{PW}$ contribution from $<S W_{N E T}>$ (Table 2). Qualitatively similar results are found from the CERES data where $<N E T_{T O A}>$ is $0.13 \mathrm{PW}$ and results from a $0.12 \mathrm{PW}$ contribution from $<O L R>$ and a $0.01 \mathrm{PW}$ contribution from $<S W_{N E T}>$ - see Table 2 .

A summary schematic of the hemispheric asymmetry of radiation at the TOA is shown in Fig. 4. We see that there is a slight deficit of net radiation in the $\mathrm{NH}$ relative to the $\mathrm{SH}$ because the $\mathrm{NH}$ emits more longwave radiation than the SH by virtue of it being slightly warmer (Kang and Seager 2013). We note that although the annual mean insolation is exactly symmetric about the equator, $<S W_{N E T}>$ can be non-zero due to hemispheric asymmetries in planetary albedo. However, we observe an almost exact (to two decimal places) equality of the hemispheric average planetary albedo despite significant differences in land mass distribution and cryospheric extent between the hemispheres. This surprising result has recently been discussed by Voigt et al. (2013). We now illustrate that planetary albedo exhibits several notable hemispheric asymmetries at regional scales but they almost entirely cancel out when averaged over the hemisphere.

We analyze regional contributions to the hemispheric asymmetries of TOA radiation by plotting the zonal mean TOA fluxes and planetary albedos as a function of the absolute value of latitude in Fig. 5; values for the $\mathrm{NH}$ are shown in the left panels while NH minus SH differences are plotted on the right (integrated values are found in Table 2).

In the tropics, there are more high convective clouds in the NH than in the SH due to the ITCZ's location north of the equator. This leads to less shortwave radiation absorbed

Table 2 Estimates of the terms in the hemispheric contrast of energy budget from the CERES and ERBE data sets

\begin{tabular}{llcl}
\hline & $<N E T_{T O A}>$ & $<O L R>$ & $<S W_{N E T}>$ \\
\hline CERES (PW) & & & \\
Total & +0.13 & +0.12 & +0.01 \\
Tropics & -0.11 & -0.31 & +0.20 \\
Subtropics & +0.27 & 0.00 & +0.27 \\
Extratropics & -0.03 & +0.43 & -0.46 \\
ERBE (PW) & & & \\
Total & +0.20 & +0.17 & +0.03 \\
Tropics & -0.11 & -0.26 & +0.15 \\
Subtropics & +0.23 & +0.01 & +0.22 \\
Extratropics & +0.08 & +0.42 & -0.34 \\
\hline
\end{tabular}

Regions-tropics, subtropics and extratropics-are marked in Fig. 5. $\left.<N E T_{T O A}\right\rangle=\left\langle O L R>+<S W_{N E T}\right\rangle$ where $<>$ is half the difference between the $\mathrm{NH}$ and $\mathrm{SH}$ integrated values. A positive value represents a deficit of TOA radiation in the $\mathrm{NH}$ 
and less longwave radiation emitted in the $\mathrm{NH}$ (because radiation is emitted from the cloud top height where temperatures are colder). In the net, the longwave asymmetry

\section{Hemispheric asymmetry of radiation}

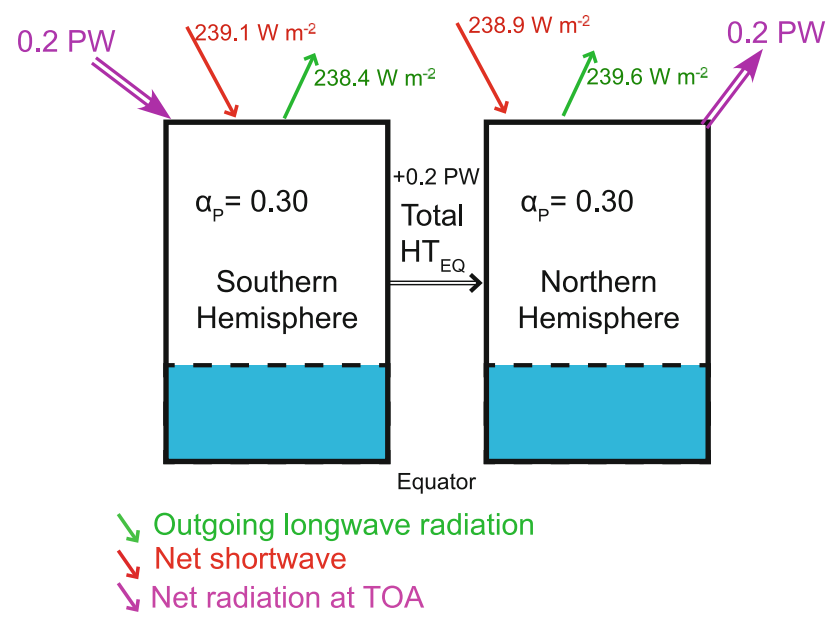

Fig. 4 TOA radiation averaged over each hemisphere and its relationship to the cross-equatorial total heat transport $\left(T H T_{E Q}=A H\right.$ $\left.T_{E Q}+O H T_{E Q}\right)$. Values represent the average of the ERBE and CERES analysis presented in this manuscript. The error bars in all fluxes are order $\pm 0.1 \mathrm{PW}$. Note that the small difference $(\sim 0.2 \mathrm{~W}$ $\mathrm{m}^{-2}$ ) in absorbed SW at TOA is the result of very slightly different hemispheric planetary albedos-the annual-mean incoming SW radiation being exactly symmetric around the Equator. The albedos are 0.298 and 0.299 for the $\mathrm{SH}$ and $\mathrm{NH}$, respectively and quoted as 0.30 in the figure in the deep tropics is larger than the shortwave one, so the ITCZ's location north of the equator is a source of energy for the NH tropics.

In the subtropics (between $17^{\circ}$ and $38^{\circ}$ ) the $\mathrm{NH}$ absorbs less shortwave radiation than the $\mathrm{SH}$ while the emitted longwave radiation is nearly equal (Fig. 5; Table 2). We can gain insight into the role of cloud and surface reflection in setting the hemispheric contrast of absorbed shortwave radiation by partitioning the planetary albedo between surface and atmospheric reflection via the method of Donohoe and Battisti (2011). The hemispheric contrast in planetary albedo in the subtropics is primarily due to the larger surface albedo in the NH of the Sahara and Arabian Deserts (Fig. 5, bottom).

In the extratropics (poleward of $38^{\circ}$ ) the $\mathrm{NH}$ absorbs more shortwave radiation than the $\mathrm{SH}$ but also emits more longwave radiation leading to a small net loss of radiation in the $\mathrm{NH}$ relative to the $\mathrm{SH}$ extratropics. This result is counter-intuitive given the abundance of land in the $\mathrm{NH}$ extratropics and the larger surface albedo of the $\mathrm{NH}$ in this region (Hummel and Reck 1979). Indeed, the surface contribution to planetary albedo is higher in the $\mathrm{NH}$ extratropics than the SH with the exception of the Antarctic continent (orange lines in the lower panels of Fig. 5). However, clouds in the southern ocean are very reflective in the shortwave (Trenberth and Fasullo 2010) and the larger cloud reflection in the $\mathrm{SH}$ relative to the $\mathrm{NH}$ extratropics as compared to the $\mathrm{NH}$ extratropics (blue lines)
Fig. 5 (Top left) The zonal and annual mean TOA radiation balance in the $\mathrm{NH}$ based on CERES. The net radiation, absorbed shortwave and emitted longwave are denoted by the black, red and green lines, respectively. (Bottom left) The planetary albedo in the $\mathrm{NH}$ and its partitioning between atmospheric and surface contributions following the method of Donohoe and Battisti (2011). The dashed vertical lines represent the boundaries of the regions analyzed in the text and Table 2. (Right panels) As on the left but differences between $\mathrm{NH}$ and $\mathrm{SH}$ are plotted
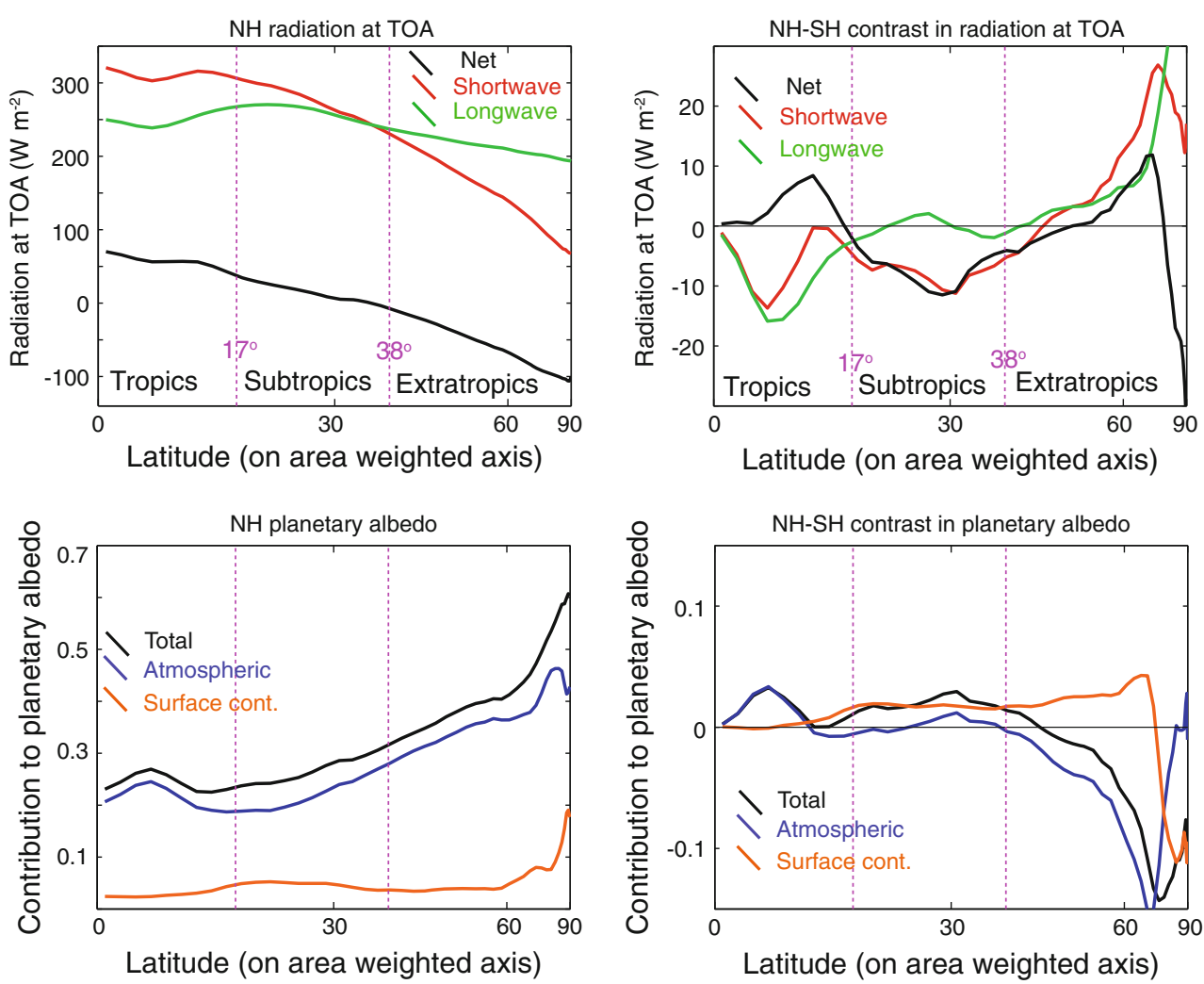
Fig. 6 (Top left) Mean SST in the Ridge solution. (Bottom left) Meridional energy transport (in PW, total and its partition between the atmosphere and ocean). (Top right) The Eulerian-mean overturning circulation in the atmosphere in Sv: the vertical red dashed line marks the equator and the black arrow marks the position of the ITCZ. (Bottom right) The residual-mean overturning circulation in the ocean (in Sv). The residual-mean circulation is the sum of the Eulerian and (parameterized) eddy-induced transports. In the right panels, clockwise and counterclockwise circulations are denoted by the red and blue shadings respectively
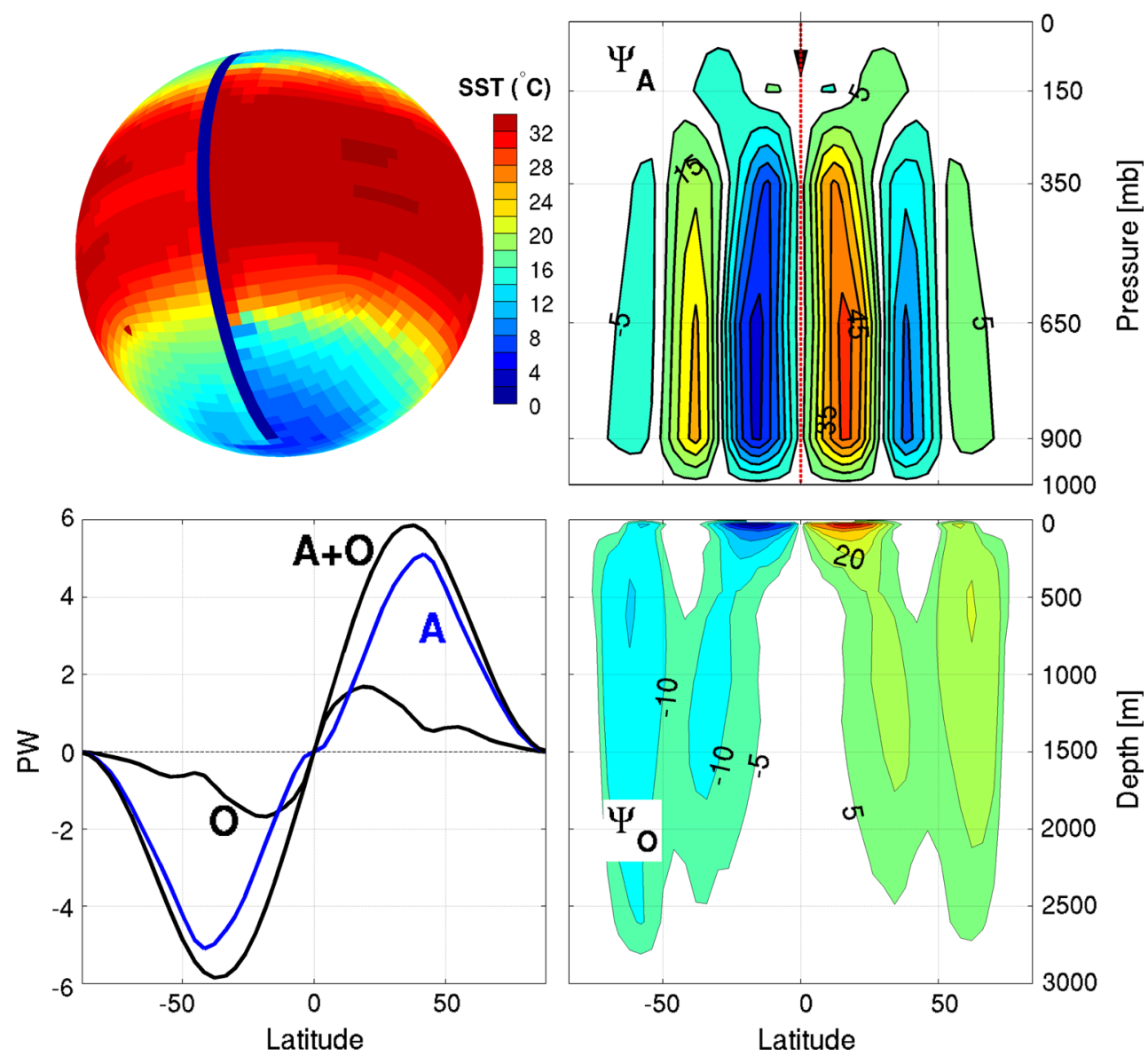

500

000

overwhelms the contrast in the surface contribution to planetary albedo. As a result, the NH extratropics absorb more shortwave radiation than its $\mathrm{SH}$ counterpart. The emitted longwave radiation in the extratropics is fairly symmetric with the exception of Antarctica. Antarctica is cold and elevated, resulting in much less longwave radiation emitted than the Arctic at comparable latitudes. The $\mathrm{NH}$ thus loses energy relative to the $\mathrm{SH}$ via longwave emission over the poles. In the net, the hemispheric contrast of radiation in the extratropics is small but results in a loss of energy in the $\mathrm{NH}$.

In summary, as set out in Table 2, there is net loss of radiation in the $\mathrm{NH}$ at the TOA and a net radiative gain in the $\mathrm{SH}$. This net radiative deficit in the $\mathrm{NH}$ must be balanced by a 0.2 PW energy transport Northward across the equator. As was noted in Sect. 2.2, the atmospheric heat transport across the equator is $0.2 \mathrm{PW}$ southward (average of all the $A H T_{E Q}$ results presented). Thus, we indirectly infer that the ocean must transport of order $0.4 \mathrm{PW}$ northward across the equator computed as a residual of the TOA radiation and the atmospheric energy flux convergence (Keith 1995). This is indeed consistent with more direct inferences of OHT based on global high-quality hydrographic data, current meters, climatological wind fields, and tracer balances-see, for example, Ganachaud and Wunsch (2000), who estimate that order $(0.4 \pm 0.2) \mathrm{PW}$ of heat is transported northward across the equator by the ocean circulation, with the Atlantic Ocean being the primary agency of transport.

\section{Studies of inter-hemispheric asymmetries of climate in an idealized coupled climate model}

The connection between ITCZ position, cross-equatorial atmosphere and ocean heat transport and interhemispheric asymmetries in net radiative forcing, can be illustrated in the simple setting of the 'aqua-planet' coupled experiments carried out by Marshall and collaborators (Marshall et al. 2007; Enderton and Marshall 2009; Ferreira et al. 2010). In these studies, a simplified coupled atmosphere/ocean/ice model is employed to study the elemental role of the ocean in climate. Geometrical constraints on ocean circulation are introduced using highly idealized land configurations in which the land-masses are reduced to 'sticks' with vanishingly-small surface area and extend from the top of the ocean to its flat bottom. More details can be found in the "Appendix". Briefly, our model resolves atmospheric eddies, has an active hydrological cycle with convection and clouds, a simplified radiation and atmospheric 
Fig. 7 As in Fig. 6 but for the Drake configuration. Note the ice cap over the south pole
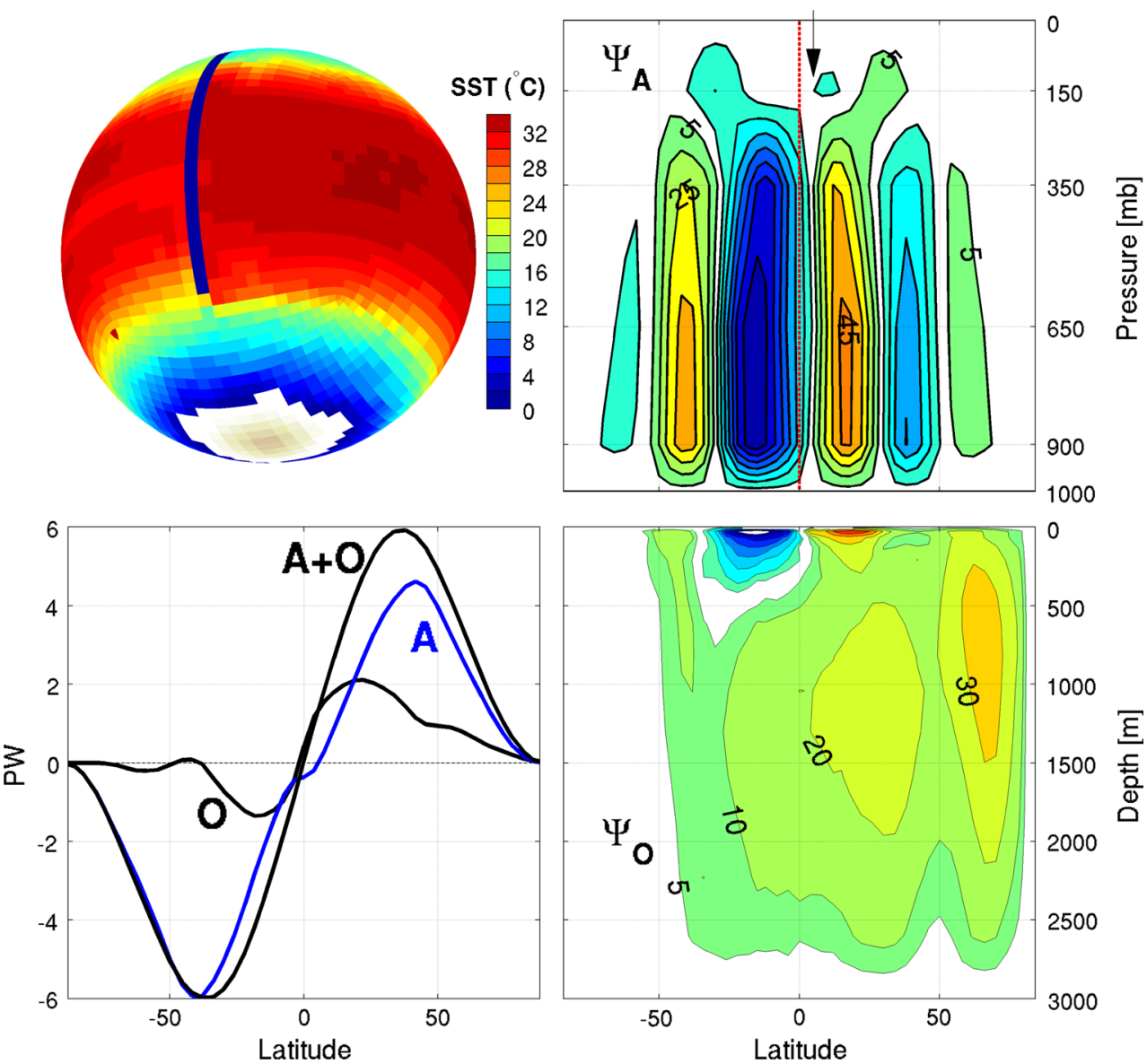

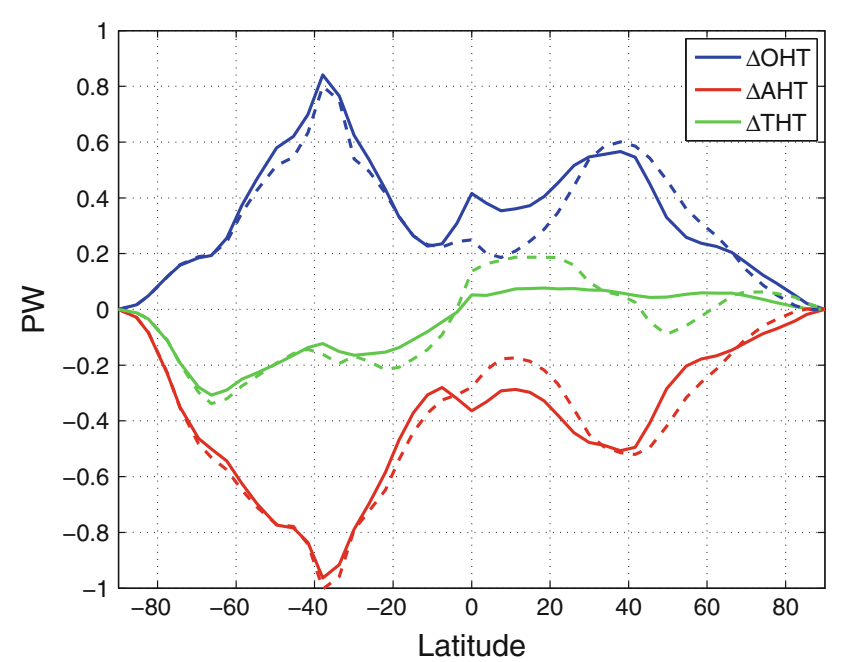

Fig. 8 Meridional energy transport difference (in PW) as a function of latitude between Drake and Ridge (solid lines) and Double Drake and Ridge (dashed lines). Atmospheric, oceanic and total energy transport differences are plotted is red, blue and green, respectively

boundary layer scheme (following Molteni 2003). The atmosphere is coupled to an ocean and sea-ice model driven by winds and air-sea heat and moisture fluxes. The coupled model is integrated forward using the same dynamical core (Marshall et al. 1997a, b, 2004) on the conformal cubed sphere (Adcroft et al. 2004). In all calculations presented here, present-day solar forcing is employed including a seasonal cycle, with present-day levels of greenhouse gas forcing.

The use of 'sticks' introduces geometrical constraints that promote one 'kind' of ocean circulation relative to another. For example, opening a channel in a meridional barrier allows a zonal jet to emerge instead of a gyre. Here we compare two coupled solutions, one in which there is a pronounced cross-equatorial heat transport in the ocean (the 'Drake' solution, Fig. 7) and one in which there is no cross-equatorial ocean heat transport (the 'Ridge' solution, Fig. 6). In Ridge, one stick of land extends from one pole to the other preventing zonal flow at all latitudes and depths and separating the ocean in to one giant basin supporting counter-rotating ocean gyres. There is no interhemispheric asymmetry in the geometry or forcing. In Drake, a gap in the ridge is opened around the south pole (south of $35^{\circ} \mathrm{S}$ ) allowing an analogue of the Antarctic Circumpolar Current to develop.

It is important to appreciate that the only difference between these two model configurations is the configuration of the sticks, one of which, 'Drake', promotes an interhemispheric overturning cell. We will now contrast the 


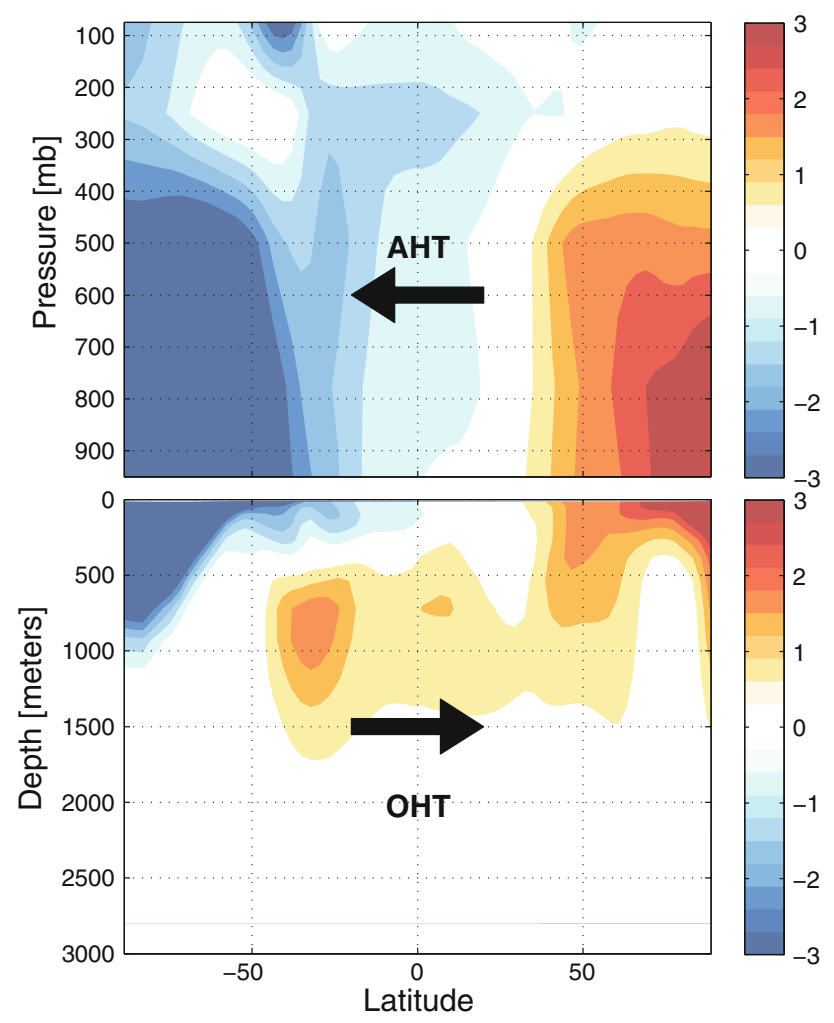

Fig. 9 Zonal-mean, time-mean potential temperature difference (in ${ }^{\circ} \mathrm{C}$ ) between the Drake and Ridge solutions. The arrows give the broad sense of energy transport in the two fluids

position of the ITCZ, energy transports and interhemispheric asymmetries in the respective climates of the two solutions. The time-mean Ridge solution shown in Fig. 6 is symmetric about the equator. In the atmosphere we observe Hadley and Ferrel Cells in each hemisphere with, in the annual-mean, an ITCZ centered directly over the equator. In the ocean, shallow, wind-driven overturning cells exist at low latitudes, whilst convectively-driven overturning cells emanate from the subpolar gyres of higher latitudes. Note that in Ridge OHT and AHT are individually zero at the equator, as they must be by symmetry. We have not observed interhemispheric 'symmetry-breaking' solutions in the Ridge configuration.

The opening of a 'Drake Passage' induces an interhemispheric overturning circulation in the ocean (see Fig. 7) with $15 \mathrm{~Sv}$ or so circulating across the equator in the meridional plane. The cell is associated with deep convection and sinking in the $\mathrm{NH}$ and upwelling to the surface through Ekman suction in the SH (see Marshall and Speer 2012). Associated with this inter-hemispheric overturning cell is a northward OHT across the equator, cooling the SH and warming the $\mathrm{NH}$. The meridional energy transport and its partition between the atmosphere and ocean has encouraging similarities with those observed in the current climate (see the discussion in Enderton and Marshall 2009).

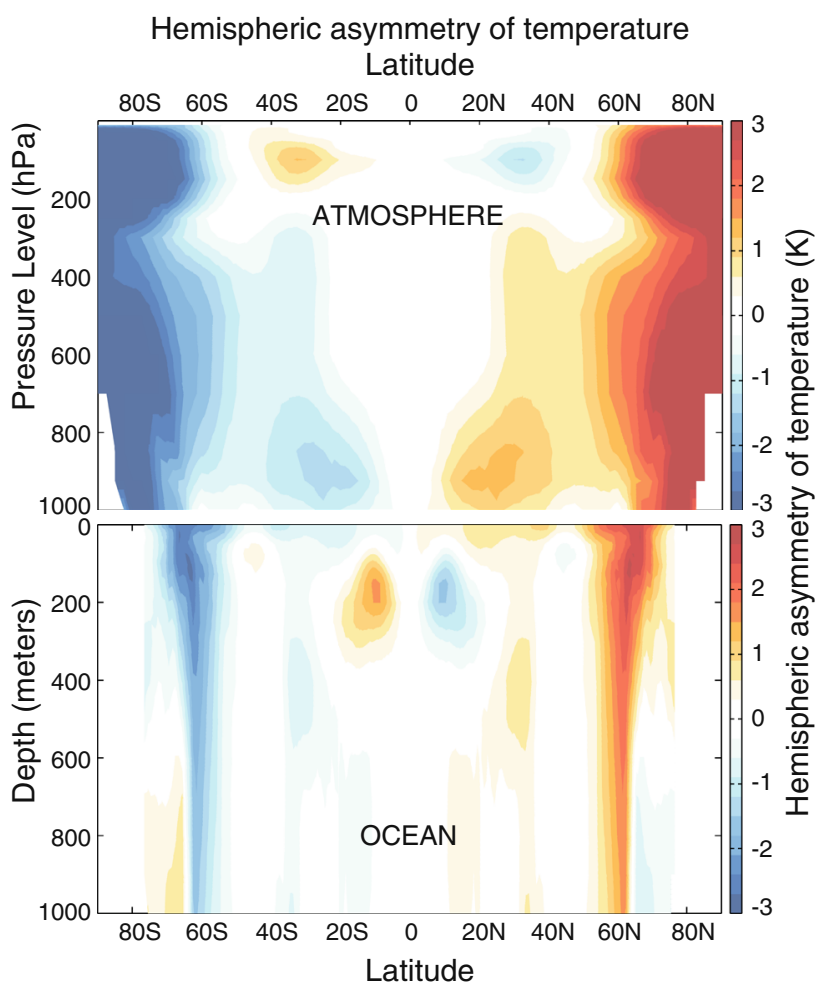

Fig. 10 Observed hemispheric asymmetry of temperature in the atmosphere and ocean (in ${ }^{\circ} \mathrm{C}$ ) computed from the NCEP reanalysis and the World Ocean Atlas. The 'asymmetric' component of a temperature field $T(\phi)$ is defined as $[T(\phi)-T(-\phi)] / 2$ where $\phi$ is the latitude

Figure 8 shows the Drake minus Ridge difference in meridional heat transports. The OHT difference is everywhere northward, with a magnitude of typically $0.4 \mathrm{PW}$. At the equator it reaches $0.4 \mathrm{PW}$, close to the observed crossequatorial heat transport discussed in Sect. 2 (perhaps fortuitously, given the simplicity of the model!). Correspondingly, the southern (northern) hemisphere of Drake is colder (warmer) than that of Ridge. Figure 9 shows the zonal-mean, time-mean potential temperature difference between the Drake and Ridge solutions in both atmosphere and ocean. These patterns are a direct result of crossequatorial heat transport in the ocean, directed up the temperature gradient in the ocean. Note that because the interhemispheric MOC cell of the ocean is mechanically forced by the wind, it has no requirement to flux energy downgradient, as discussed in Nycander et al. (2007). The atmosphere, by contrast, fluxes heat across the equator from the warmer $\mathrm{NH}$ to the (somewhat) colder $\mathrm{SH}$-as indicated by the arrows in the figure. An ice cap appears at the Southern Pole of Drake resulting in SH cooling being slightly greater than the $\mathrm{NH}$ warming. Notably, the meridional atmospheric transport difference is everywhere southward, almost exactly mirroring the OHT difference. As a result, the total heat transport difference (green) is 
relatively small at the equator $(<0.05 \mathrm{PW})$. Note how the annual-mean overturning circulation in the tropical atmosphere shifts northward in Drake to achieve a southward heat transport: as can be seen by comparing Figs. 6 and 7, the SH Hadley cell in Drake is stronger than in Ridge and extends into the $\mathrm{NH}$, and the Drake Hadley cell of the $\mathrm{NH}$ is weaker. The $A H T_{E Q}(0.36 \mathrm{PW})$ is mostly achieved by the annual mean MOC (0.3 PW). In other words the time-mean position of the ITCZ is shifted slightly northwards in Drake relative to Ridge to achieve the necessary heat transport. This asymmetry in the position and strength of the Hadley cells is in broad agreement with observations of the current climate—see, e.g., Fig. 3.

The small difference in total heat transport between Drake and Ridge can be rationalized in terms of the TOA radiation (not shown). Except over the SH icecap, we observe that changes in $S W_{N E T}$ and OLR closely compensate one-another leading to only small (few $\mathrm{W} \mathrm{m} \mathrm{m}^{-2}$ ) changes in net TOA radiation. ${ }^{3}$ Changes in $S W_{N E T}$ are associated with changes in cloud fraction (CF) which in turn appear to be related to the change in the subtropical subsidence/upwelling patterns. Note that in Drake, the NH TOA albedo is 0.276 and $\mathrm{SH}$ albedo is 0.282 (i.e. $<S W_{N E T}>\leq 0$ ), a $2 \%$ difference, larger than seen in the observations but perhaps not dissimilar within error bars (see Fig. 4). However, as in the observations, the OLR effect dominates with more OLR emission in the NH than in the $\mathrm{SH}(<O L R>\geq 0$, as expected from the higher $\mathrm{NH}$ temperatures, see Fig. 9), allowing for a small northward cross-equatorial total heat tranpsort in Drake.

The shift of the ITCZ in the Drake solution described here is also a property of more complex models such as the Double Drake described in Ferreira et al. (2010). In that solution there is a small basin and a large basin, together with a Drake passage opening. Due to a reorganization of the hydrological cycle and the salinity budget, the interhemispheric overturning circulation in the ocean becomes confined to the saltier small basin (which we can think of as the Atlantic) and the cross-equatorial ocean heat transport is carried in the small basin, as in the Atlantic of the present climate. The heat transport anomalies between Double Drake and Ridge are also plotted in Fig. 8 and are remarkably similar to Drake minus Ridge despite the crossequatorial heat transport being carried almost entirely in the small basin in Double Drake. The ITCZ, however, shifts North of the equator at all latitudes.

\footnotetext{
${ }^{3}$ We observe a strong anti-correlation between $S W_{N E T}$ and cloud fraction $(\mathrm{CF})$ everywhere northward of $60^{\circ} \mathrm{S}$, with a $1 \%$ increase in $\mathrm{CF}$ resulting in a $1 \mathrm{~W} \mathrm{~m}^{-2}$ decrease in $S W_{N E T}$. This can be understood by writing $S W_{N E T}=S_{o} / 4 \times\left(1-\alpha_{p}\right)$, and so $\Delta S W_{N E T}=-S_{o} / 4 \times$ $\Delta \alpha_{p}$ with $\Delta \alpha=\alpha_{c l} \Delta C F$ assuming variations of the planetary albedo $\alpha_{p}$ are dominated by CF variations $\left(\alpha_{c l}=0.4\right)$. Then, if $\Delta C F=1 \%, \Delta S W_{N E T}=1366 / 4 \times 0.4 \times 0.01 \sim 1 \mathrm{~W} \mathrm{~m}^{-2}$ ).
}

Finally, it should be noted that in our idealized coupled calculations the interhemispheric MOC, and hence crossequatorial OHT and shifted ITCZ, are promoted by opening up Drake passage. Although we do believe that Drake passage plays a major role in allowing cross-equatorial OHT, other factors certainly play a role in Nature. The important point here is that, if significant quantities of heat are carried across the Equator by the ocean, the ITCZ will shift to compensate.

\section{Discussion and conclusions}

We have argued, and illustrated in observations and models, that because hemispheric net TOA radiative forcing of the climate is almost perfectly symmetric about the equator, the total (atmosphere plus ocean) heat transport across the equator is small (order 0.2 PW). However, due to the ocean's (and in fact the Atlantic's) MOC, the ocean carries a significant amount of heat across the equator (order $0.4 \mathrm{PW}$ ). There are two primary consequences. First AHT is southwards across the equator to compensate $(0.2 \mathrm{PW}$ southwards), resulting in the ITCZ being displaced north of the equator. Secondly, the atmosphere, and indeed the ocean, is slightly warmer (by perhaps $2{ }^{\circ} \mathrm{C}$ ) in the $\mathrm{NH}$ than in the SH. This leads to the NH emitting slightly more OLR radiation than the $\mathrm{SH}$ by virtue of its relative warmth (Kang and Seager 2013) supporting the small northward heat transport by the coupled system across the equator.

Figure 10 shows the 'asymmetric' component of the observed pattern of zonal-average temperature in the atmosphere and ocean, and should be compared to Fig. 9 from our coupled model. The warmth of the NH oceans and atmosphere relative to the SH is readily apparent in both observations and models. As discussed in, for example, Yoshimori and Broccoli (2009) and Frierson et al. (2013), the ITCZ's location north of the equator is perfectly consistent with, and indeed is a consequence of, the atmosphere being heated more strongly in the $\mathrm{NH}$ than in the $\mathrm{SH}$. This heat is primarily supplied by the ocean rather than absorbed short-wave radiation due to interhemispheric asymmetries in albedo.

In our coupled model we found that opening up a Drake passage leads to an inter-hemispheric overturning pathway in the ocean supplied by deep convection in the north and wind-driven upwelling in the south. This overturning circulation transports heat northward, cooling the $\mathrm{SH}$ and warming the NH. The atmosphere returns the OHT associated with the inter-hemispheric mode southward by shifting its ITCZ northward. Consistently, the total (atmosphere plus ocean) change on moving from Drake to Ridge is very small. This is because $S W_{N E T}$ and OLR tend to oppose one-another, a link that involves cloud-albedo feedback. Change in cloud cover is triggered by circulation 
changes: more clouds lead to less $S W_{N E T}$ but also less OLR. Although the compensation between the longwave and shortwave effects appear to be sound, the underlying details remain uncertain.

The study presented here is complementary to that of Frierson et al. (2013). There an atmosphere-only model is used to study shifts of the tropical circulation pattern in response to prescribed lateral ocean heat fluxes through a mixed layer to which the atmosphere is coupled. Here, in contrast, a fully coupled model is used and geometrical constraints are used to study two different coupled climates, one in which cross-equatorial heat fluxes are allowed and one in which they are not. In this way Hadley circulation shifts are realized dynamically as part of coupled climate dynamics and thermodynamics.

To conclude we mention two outstanding uncertainties and incomplete aspects that need to be clarified in future work. Firstly, a major issue is our lack of knowledge of the degree to which, and the reasons why, there is compensation in inter-hemispheric atmospheric and ocean heat transport. Compensation is also a property of the present climate (and it is complete to within observational error bars) but does this have to be the case? Compensation is certainly a property of the coupled model we have studied here and is also seen in the CMIP3 ensemble (Donohoe et al. 2012). But the underlying cause remains uncertain. Secondly, as alluded to in Sect. 2, observations do suggest that the atmosphere carries energy south across the equator, but it is not clear that this is mainly achieved, as one would naively expect, by the atmosphere's overturning circulation i.e. by the Hadley Cell. As shown here and in previous work by Heaviside and Czaja (2012), standing eddies appear to play a major role in cross-equatorial heat transport.

\begin{abstract}
Acknowledgments We would like to thank many people for discussions over the past year as this study emerged: in particular Arnaud Czaja, Dargan Frierson, Isaac Held, George Philander, Richard Seager and Rong Zhang. A.D. was supported by a NOAA postdoctoral fellowship and J.M., D.F. and D.M. by the National Science Foundation and NOAA. This study was first presented during the Philander Symposium at Princeton University in September 2012. We thank George Philander for his inspiration and encouragement to tackle questions such as these.
\end{abstract}

Open Access This article is distributed under the terms of the Creative Commons Attribution License which permits any use, distribution, and reproduction in any medium, provided the original author(s) and the source are credited.

\section{Appendix}

The MITgcm (Marshall et al. 1997a, b) is used in a coupled ocean-atmosphere-sea ice configuration. The model exploits an isomorphism between ocean and atmosphere dynamics to generate an atmospheric GCM and an oceanic
GCM from the same dynamic core (Marshall et al. 2004). All components use the same cubed-sphere grid at a low resolution $\mathrm{C} 24$, yielding a resolution of $3.75^{\circ}$ at the equator (Adcroft et al. 2004). The cubed-sphere grid avoids problems associated with the converging meridian at the poles and ensures that the model dynamics at the poles are treated with as much fidelity as elsewhere.

The atmospheric physics is of 'intermediate' complexity, based on the "SPEEDY" scheme (Molteni 2003) at low vertical resolution (5 levels, one in the stratosphere, three in the troposphere and one in the boundary layer). Briefly, it comprises a 4-band radiation scheme, a parametrization of moist convection, diagnostic clouds and a boundary layer scheme. The 3-km deep, flat-bottomed ocean model has 15 vertical levels, increasing from $30 \mathrm{~m}$ at the surface to $400 \mathrm{~m}$ at depth. Effects of mesoscale eddies are parametrized as an advective process (Gent and McWilliams 1990) and an isopycnal diffusion (Redi 1982), both with a transfer coefficient of $1,200 \mathrm{~m}^{2} \mathrm{~s}^{-1}$. Convective adjustment, implemented as an enhanced vertical mixing of temperature and salinity, is used to represent ocean convection (Klinger et al. 1996). The background vertical diffusion is uniform and set to $3 \times 10^{-5} \mathrm{~m}^{2} \mathrm{~s}^{-1}$.

The sea-ice model is based on Winton (2000)'s two and a half layer thermodynamic model with prognostic ice fraction, snow and ice thickness (employing an energy conserving formulation). There is no sea-ice dynamics. The land model is a simple 2-layer model with prognostic temperature, liquid ground water, and snow height. There is no continental ice. The $\mathrm{CO}_{2}$ level is held at present day values. The seasonal cycle is represented (with a $23.5^{\circ}$ obliquity and zero eccentricity) but there is no diurnal cycle.

Finally, note that, as discussed by Campin et al. (2008), the present coupled ocean-sea ice-atmosphere model achieves perfect (machine-accuracy) conservation of freshwater, heat and salt during extended climate simulation. This is made possible by the use of the rescaled height coordinate $z^{\star}$ (Adcroft and Campin 2004) which allows for a realistic treatment of the sea ice-ocean interface. This property is crucial to the fidelity and integrity of the coupled system. The set-up is identical to that used in Ferreira et al. (2010), (2011) and very similar to that of Marshall et al. (2007) and Enderton and Marshall (2009) (see Ferreira et al. (2010) for key differences).

\section{References}

Adcroft A, Campin JM (2004) Re-scaled height coordinates for accurate representation of free-surface flows in ocean circulation models. Ocean Modell 7:269-284

Adcroft A, Campin J, Hill C, Marshall J (2004) Implementation of an atmosphere-ocean general circulation model on the expanded spherical cube. Mon Wea Rev 132:2845-2863 
Barkstrom B, Harrison E, Smith G, Green R, Kibler J, Cess TESTR (1989) Earth radiation budget (erbe) archival and april 1985 results. Bull Am Meteorol Soc 70:1254-1262

Barkstrom BR, Hall JB (1982) Earth radiation budget experiment (erbe) - an overview. J Energy 6:141-146

Broccoli AJ, Dahl KA, Stouffer RJ (2006) Response of the itcz to northern hemisphere cooling. Geophys Res Lett 33:L01702. doi: 10.1029/2005GL024546

Campin JM, Marshall J, Ferreira D (2008) Sea ice-ocean coupling using a rescaled vertical coordinate $z^{\star}$. Ocean Modell 24:1-14

Czaja A, Marshall JC (2006) The partitioning of poleward heat transport between the atmosphere and ocean. J Atmos Sci 63:1498-1511

Donohoe A, Battisti DS (2011) Atmospheric and surface contributions to planetary albedo. J Clim 24:4402-4418

Donohoe A, Marshall J, Ferreira D, McGee D (2012) The relationship between itcz location and cross equatorial atmospheric heat transport; from the seasonal cycle to the last glacial maximum. J Clim (accepted)

Enderton D, Marshall J (2009) Explorations of atmosphere-ocean-ice climates on an aqua-planet and their meridional energy transports. J Atmos Sci 66:1593-1611

Fasullo JT, Trenberth KE (2008) The annual cycle of the energy budget: part 1. Global mean and land-ocean exchanges. J Clim 21:2297-2312

Fasullo JT, Trenberth KE (2008) The annual cycle of the energy budget: part 2. Meridional structures and poleward transports. J Clim 21:2313-2325

Ferreira D, Marshall J, Campin JM (2010) Localization of deep water formation: role of atmospheric moisture transport and geometrical constraints on ocean circulation. J Clim 23:1456-1476

Ferreira D, Marshall J, Rose B (2011) Climate determinism revisited: multiple equilibria in a complex climate model. J Clim 24:992-1012

Frierson DMW, Hwang YT (2012) Extratropical influence on itcz shifts in slab ocean simulations of global warming. J Clim 25:720-733

Frierson DMW, Hwang YT, Fuckar N, Kang RSS, Donohoe A, Maroon E (2013) Why does tropical rainfall peak in the northern hemisphere? The role of the oceans meridional overturning circulation. Nature (submitted)

Fuckar NS, Xie SP, Farneti R, Maroon E, Frierson DMW (2013) Influence of the extratropical ocean circulation on the intertropical convergence zone in an idealized coupled general circulation model. J Clim (accepted)

Ganachaud A, Wunsch C (2000) Improved estimates of global ocean circulation, heat transport and mixing from hydrographic data. Nature 408:453-457. doi:10.1038/35044048

Gent PR, McWilliams JC (1990) Isopycnic mixing in ocean circulation models. J Phys Oceanogr 20:150-155

Heaviside C, Czaja A (2012) Deconstructing the heat transport by the hadley cell. Q J R Meterol Soc (accepted)

Held I (2001) The partitioning of the poleward energy transport between the tropical ocean and atmosphere. J Atmos Sci 58:943-948

Hummel J, Reck R (1979) A global surface albedo model. J Appl Meteorol 18:239-253

Kalnay E, Coauthors (1996) The NCEP/NCAR 40-year reanalysis project. Bull Am Meteorol Soc 77:437-472

Kang SM, Seager R (2013) Croll revisited: why is the northern hemisphere warmer than the southern hemisphere? http:// academiccommons.columbia.edu/catalog/ac: 153364

Kato S, Loeb N, Minnis P, Francis J, Charlock T, Rutan D, Clothiaux E, Sun-Mack S (2006) Seasonal and interannual variations of top-of-atmosphere irradiance and cloud cover over polar regions derived from ceres data set. Geophys Res Lett 33. doi:10.1029/ 2006GL026685
Keith D (1995) Meridional energy transport: uncertainity in zonal mean. Tellus 47:30-44

Klinger BA, Marshall J, Send U (1996) Representation of convective plumes by vertical adjustment. J Geophys Res C8(101):18175-18182

Lorenz E (1953) A multiple index notation for describing atmospheric transport processes. Geophys Res Pap 53:100-110

Marshall J, Speer K (2012) Closure of the meridional overturning circulation through southern ocean upwelling. Nat Geosci 5:171-180. doi:10.1038/ngeo1391

Marshall J, Adcroft A, Hill C, Perelman L, Heisey C (1997) A finitevolume, incompressible navier stokes model for studies of the ocean on parallel computers. J Geophys Res 102(C3):5753-5766

Marshall J, Hill C, Perelman L, Adcroft A (1997) Hydrostatic, quasihydrostatic, and nonhydrostatic ocean modeling. J Geophys Res 102(C3):5733-5752

Marshall J, Adcroft A, Campin JM, Hill C, White A (2004) Atmosphere-ocean modeling exploiting fluid isomorphisms. Mon Wea Rev 132:2882-2894

Marshall J, Ferreira D, Campin J, Enderton D (2007) Mean climate and variability of the atmosphere and ocean on an aquaplanet. J Atmos Sci 64:4270-4286

Molteni F (2003) Atmospheric simulations using a GCM with simplified physical parametrizations. I: model climatology and variability in multi-decadal experiments. Clim Dyn 64:175-191

Nycander J, Nilsson J, Doos K, Brostrom G (2007) Thermodynamic analysis of ocean circulation. J Phys Oceanogr 37:2038-2052. doi:10.1175/JPO3113.1

Philander SGH, Gu D, Halpern D, Lambert G, Lau NC, Li T, Pacanowski RC (1996) Why the itcz is mostly north of the equator. J Clim 9:2958-2972

Priestley C (1948) Heat transport and zonal stress between latitudes. Q J R Meteorol Soc 75:28-40

Redi MH (1982) Oceanic isopycnal mixing by coordinate rotation. J Phys Oceanogr 12:1154-1158

Trenberth KE, Fasullo JT (2010) Simulation of present day and 21st century energy budgets of the southern oceans. J Clim 23:440-454

Trenberth KE, Smith L (2008) Atmospheric energy budgets in the Japanese reanalysis: evaluation and variability ? J Meteorol Soc Japn Ser II 86(5):579-592

Trenberth KE, Stepaniak DP (2003) Co-variability of components of poleward atmospheric energy transports on seasonal and interannual timescales. J Clim 16:3691-3705

Trenberth KE, Fasullo JT, Kiehl J (2009) Earth's global energy budget. Bull Am Meteorol Soc 90:311-324

Voigt A, Stevens B, Bader J, Mauritsen T (2013) The observed hemispheric symmetry in reflected shortwave irradiance. J Clim 26:468-477

Waliser D, Gautier C (1993) A satellite-derived climatology of the itcz. J Clim 6:2162-2174

Wielicki B, Barkstrom B, Harrison E, Lee R, Smith G, Cooper J (1996) Clouds and the earth's radiant energy system (ceres): an earth observing system experiment. Bull Am Meteorol Soc $77: 853-868$

Winton M (2000) A reformulated three-layer sea ice model. J Atmos Ocean Technol 17:525-531

Xian P, Miller R (2008) Abrupt seasonal migration of the itcz into the summer hemisphere. J Atmos Sci 65:1678-1695

Xie P, Arkin P (1996) Analyses of global monthly precipitation using gauge observations, satellite estimates, and numerical model predictions. J Clim 9:840-858

Yoshimori M, Broccoli A (2009) On the link between hadley circulation and radiative feedback processes. Geophys Res Lett 36:L20701

Zhang R, Delworth T (2005) Simulated tropical response to a substantial weakening of the atlantic thermohaline circulation. J Clim 18:1853-1860. doi:10.1175/JCLI3460.1 